\title{
Effectiveness of term projects in helping students to connect theory with practice: An evaluation of students' perspectives
}

\author{
Israel Dunmade \\ Department of Environmental Science, Mount Royal University, Calgary, Canada
}

Email address:

israel_dunmade@yahoo.ca (I. Dunmade)

\section{To cite this article:}

Israel Dunmade, Effectiveness of Term Projects in Helping Students to Connect Theory with Practice: an Evaluation of Students' Perspectives. Education Journal. Vol. 2, No. 1, 2013, pp. 1-6. doi: 10.11648/j.edu.20130201.11

\begin{abstract}
The purpose of this study is to evaluate the effectiveness of term project in helping students to connect theory with practice. A term project is a hands-on assignment that require students to apply ideas, theories, concepts, or principles learned or studied in class to a new situation/real life scenario. Term projects in ENVS 4413 Principles of eco-industrial development are designed to help students connect theory with practice. The aim is to enhance students' learning of the course materials and to give them experiential knowledge of how the course materials are applied in the workplace. Students' survey and students' reflective journals are among the data gathering methods used. They were incorporated components of the ENVS 4413 course. Qualitative and quantitative methods were used in analyzing how term project help students to connect theory with practice. The survey data was statistically analyzed to provide quantitative evidence on whether term project helps students to connect theory with practice or not. Reflective journal provided observational data for an explanation of survey findings. Data analysis showed that students found the term project helpful in connecting theory with practice. They found industrial visit to partnering companies to be the most helpful aspect of the term project. Data collection and conceptual model development were the least interesting aspect to them. It can be concluded from students' perspectives that term project is helping students to connect theory with practice. This assures the compliance of the Bachelor of Applied Environmental Science (BAES) degree program with the original program design and facilitates the success of MRU's BAES degree students.
\end{abstract}

Keywords: Problem-Based Learning, Collaborative Project-Based Learning, Environmental Education, Principles Of Eco-Industrial Development, Term Project, Applied Degree Program, Connecting Theory With Practice

\section{Introduction}

This study involves an assessment of the effectiveness of term project in helping applied environmental science degree students to connect theory with practice. A term project is a hands-on assignment that require students to apply ideas, theories, concepts, or principles learned or studied in class to a new situation/real life scenario. It is a form of project based learning method [1]. Employment of term project instrument in environmental education became necessary in view of some changes in post secondary education policy in Alberta some years ago.

Some of the changes in Alberta's post secondary education policy in the 1990s were made in order to satisfy the need for more middle level power especially in Northern Alberta. The need for more environmental professionals came as a result of an ever increasing environmental awareness all over the world. This includes the awareness of the enormity of our resource consumption, environmental releases, and the potential consequences. The consciousness of the implications of resource consumption and of the releases trend on human and industrial ecosystem welfare both in the near and distant future has led to increased advocacy for environmental stewardship. As a result, proactive manufacturing industries, government agencies and other stakeholders are taking steps to reduce our ecological footprints. However, the skills and expertise of environmental scientists are needed in order to adequately address environmental issues resulting from our economic activities. The increasing expansion of our economic activities in Alberta necessitates the recruitment of more and more environmental scientists. Environmental scientists are needed by governmental agencies to formulate, monitor and enforce 
environmental policies. They are also needed in the oil and gas industry and other sectors of the economy to help in developing innovative approaches that reduce the ecological footprints of our industrial activities. Sufficient number of environmental scientists needed to meet these demands is usually in short supply. Consequently, applied environmental degree programme, like other applied degree programmes, was developed to address the training needs. The four-year applied environmental degree program was designed to provide a good balance of theory, applied coursework, arts and science courses, and hands-on experience. The principles of eco-industrial development course (EID) is a fourth year capstone applied coursework designed to facilitate students ability to not only be able to connect theories learned in the course but in other courses taken by students in the program with their real world applications.

\subsection{Theory and Its Uses}

Before we can talk of application of theory we need to understand the purpose of theory. It is also important to know what it means to connect theory with practice, what is involved and how it can be realized. In [2], theory was defined as "a schema of interrelated concepts which are empirically verifiable." He also articulated four uses of theory. According to Gitterman [2], theory:

- "Provides a frame of references which simultaneously focuses and circumscribes our observations",

- "Provides us with a classification scheme to organize our observations", thereby fixes our attention and keeps us from wandering all over the place",

- "Allows us to conceptualize and consolidate our observations, and through the "short-cut" of a concept we are able to describe and to discuss phenomena parsimoniously", and

- "Enables us to recognize and predict behavior because it has identified observable patterns, that is, empirical uniformities and ascribed meaning to them".

\subsection{Connecting Theory with Practice}

So, theory is a platform or basis for practical applications. Connecting theory with practice can be explained from two perspectives. One can explain it from theory to practice or from linking practice to theory. Taking the second perspective, connecting theory with practice means being able to diagnose a given problem situation, recollect previously learned theory or studies carried out for addressing similar problem and then making appropriate draw of suitable concept(s) out of many concepts learned to address the real life problem.

Teaching students how to connect theory with practice is necessary because many of the post secondary education curriculums "tend to communicate a fragmented view of knowledge, both in coursework and in field experiences" [3] Teaching students how to employ theory with appropriate application has many benefits. One of the benefits is that it will enable them to be able to "hit the ground running" as soon as they start their professional career. It will also reduce the length of post graduation training required before their employers can commit professional duties to their hands. In addition, it will reduce training cost to the employer. Moreover, it will increase their overall productivity in the workplace. A number of other scholars such as Harris [4], Higgins and Morgan [5], and Gunder [6] have done some work on relating theory with practice in various professions.

\subsection{The Process of Connecting Theory with Practice}

Teaching students to identify and connect appropriate theory with the right application is challenging. In recognizing this challenge, Gittermann [2] said "a natural or easy connection does not exist between theory and practice" However there are a number of steps that could be taken to overcome the challenges in order to achieve the desired goal. He then provided an insight on how the challenge could be overcome. He said "the very act of making connections between theory and practice requires the student to face the task of bridging the abstract and real worlds". He also said that "teaching students to connect theory and practice requires helping them to break through theoretical and personal boundaries, cultivating their natural curiosity and spontaneity". Furthermore, He opined that it requires allowing "the student to define problems interactionally rather than individually, and with the instructor, risk and explore that which is less known, less developed, less structured and less certain".

\subsection{Bridging the Abstract and Real Worlds}

How then can teachers help students to break through theoretical and personal boundaries, cultivate their natural curiosity, and bridge the abstract and real worlds? What are the activities and approaches that facilitates students' ability to connect theory with practice? Different scholars have tried and advocated varied strategies for developing students as evolving professionals. In [7], it was explained that the gap between theory and practice can be bridged by providing students "with multiple opportunities to apply what they have learned in meaningful contexts". They also supported the view that "site-based experience provides students (i.e. "professionals in the making") with more opportunities to successfully apply what they are learning within the context of the classroom."

It is believed that such multiple opportunities for students to apply what they have learned in meaningful context can be provided by designing and implementing an assemblage of activities that take place both in the class and at some sites where they are likely to work as professionals. According to American Association for the Advancement of Science [8], such activities should be "tangible and directly accessible to their senses-visual, auditory, tactile, and kinesthetic." "With experience in such activities, students would grow in their ability to understand abstract concepts, manipulate symbols, reason logically, and generalize." This was supported in [9], where it was opined that "optimal learning 
occur for students as evolving professionals when they are provided with experiences to translate the theory and practice gained into tangible outcomes for their clients."

Term projects in the principles of eco-industrial development course at Mount Royal University was designed to achieve the goal of bridging the gap between theory and practice by giving students opportunities to apply what they learned in class in the industrial setting.

\section{Context}

Mount Royal University is a mid-size undergraduate university in Western Canada. It offers a variety of bachelor degrees in Arts, Business, Education, Nursing, and Science. The University also offer applied degrees in Business \& Entrepreneurship - Sport \& Recreation, Child Studies, Ecotourism \& Outdoor Leadership, Interior Design, and Environmental Science. ENVS 4413 Principles of eco-industrial development course is one of the capstone courses in the 4 year applied environmental science degree program at Mount Royal University. It was designed to enable students to harmonize and apply the knowledge they acquired in various courses in a real life situation. Eco-industrial development (EID) is a win-win preventive approach to environmental protection. An eco-industrial development could either involve the development of an eco-industrial park or an eco-industrial network. It could also involve the conversion of an existing industrial park or Brownfield to an eco-industrial park or network. Eco-industrial park (EIP) is the most preferred of the three ways of implementing EID. This is because it has the highest environmental benefits. However, eco-industrial network (EIN) is the easiest to implement because of its lowest financial requirement.

An eco-industrial park (EIP) is a group of businesses that are co-located in a geographical location for the purpose of sharing mutual benefits [10-12]. In an EIP, wastes or by-products of one company serves as input for another company that is on the same location. Businesses in such park are pre-selected to ensure the existence or possibility of synergetic relationship between them. The relationship is usually formalized at the onset of the co-location.

An eco-industrial network (EIN) is also a group of businesses with or without formal agreement that they will take each others' wastes for conversion into value-added products, thereby eliminating the need to send those wastes to a landfill, an incinerator or a wastewater treatment plant. Such collaboration(s) could also be facilitated by a third party. Businesses involved may be at the same location or they may be at different geographical locations. However, they are usually not far apart. They are often in the same region. This approach to implementing EID is also called virtual eco-industrial park (Virtual EIP) [12].

An Industrial park is a group of businesses co-located on the same piece of land. Industrial parks are designed to enable businesses at the location to share the same infrastructure but they may have or may not have any relationship with one another. Brownfield is a piece of property that has been abandoned or under-utilized due to contamination or perceived contamination. This kind of property can be converted to either an eco-industrial park or an eco-industrial network.

By teaching this course, students that graduate from the applied environmental degree program were expected to apply the knowledge acquired in the course and in the program to help their employers and the community at large to reduce the ecological footprint of our economic activities.

The course structure is a mixture of lectures, a group assignment, a mid-term exam, a term project, and the final exam. The mixture was aimed at giving students experiential learning that would bridge the gap between theory and practice. Various theories of eco-industrial development were taught in a two hour lectures per week for 10 weeks in the semester. The group assignment part of the course involved dividing students into groups of three students and assigning each group to study an existing eco-industrial parks and eco-industrial networks. Each group then present their findings to the class at the end of the three weeks period.

\subsection{Term Project}

Term project component of ENVS 4413 course consisted of five activity-based reflective journals, an industrial visit, group discussions, final report writing, and a group presentation.

\subsubsection{Industrial Visit}

It involved dividing students into groups of 3-4 students on the first day of the class. Each group was assigned a partnering company from which they were to collect information required for the term project. The industrial visit thus gave the students an opportunity to observe the company's manufacturing process, their materials and energy consumption, and wastes generated in the process. In addition, it gave them the opportunity to ask questions about various operational challenges the company was facing, what has been done to address the issues and how effective such attempts has been.

\subsubsection{Group Discussions}

Two types of term project related discussions were held in the class during the course. The first was intra group discussions held to develop strategy for negotiations with other groups, to develop conceptual eco-industrial network (EIN) model and to do cost benefit analysis of the EIN model developed by the group. The other one was inter-group discussions which involve bilateral business-like negotiations between the groups to identify possible areas of cooperation. These second type of discussion was also aimed at evaluating merits and demerits of such cooperation. The group discussion component was designed to give students experiential knowledge of what it takes to identify, evaluate and negotiate business deals of mutual benefits to all the partners.

This study was approved by Mount Royal University Human Resources Ethics Board. Participants in the study 
were final year bachelor of applied environmental science degree students. 19 out of the 23 students that enrolled in the course participated in the study. Written consent to analyze students' reflective writing, end-of-semester survey, term project reports, and exam answer scripts were obtained on the first day of the class. The required data was collected in the Fall 2010.

\section{Methodology}

Varieties of data collection instruments and course activities were designed to facilitate being able to answer the following three research questions:

- Does term project help students to connect theory with practice or not?

- How does term project help students to connect theory with application? and

- Which of the activities/aspects of the term project are valuable in helping students connect theory with practice?

Two of the four data gathering methods used in this study were activity-based reflective journals and end of semester survey.

\subsection{Reflective journal}

Activity-based reflective journaling was incorporated into this course to promote learning and transformation. This was based on the scholarly works by various authors on its usefulness in promoting learning. For instance, Tsang [9] said "being a reflective practitioner is a highly desirable attribute for professionals because it signifies quality assurance through a sustained cyclical process of self-examination, self evaluation, self-directed learning, enlightenment, self-optimization and transformation." Her opinion was premised on [10] where it was said that "students learn best by thinking, evaluating, integrating and internalizing insights gained from their various experiences." Consequently, five activity-based structured reflective reports were among the four sources of data collected for this study. Each student enrolled in the course was required to submit a reflective report after each of the following activities that were designed to help students connect theory with practice: i) after the introduction of the course, ii) after industrial visit, iii) after the group assignment findings were presented in the class, iv) after group discussions involving negotiations and modeling of conceptual eco-industrial network, and v) after term project report has been submitted and each group have made their presentation on the term project.

\subsection{End of Semester Survey}

Students were given a set of quantitative and qualitative questions on the last day of class in the semester regarding their experience and perception on the course and individual course components. Students' comments and the rating of course components in the end-of-semester survey were analyzed in assessing student's perception of their ability to connect theory with practice.

\section{Results and Discussion}

The results of this study are discussed below. Figure 1 shows students' preference ratings of the course components they liked most and Figure 2 shows course components that are of least interest to them.

Majority of students indicated in their course components rating and in their comments that industrial visit helped them most in connecting theory with practice. This is evident in Figure 1. Further analysis of the students' survey showed in Figure 2 that data collection was of least interest to them.

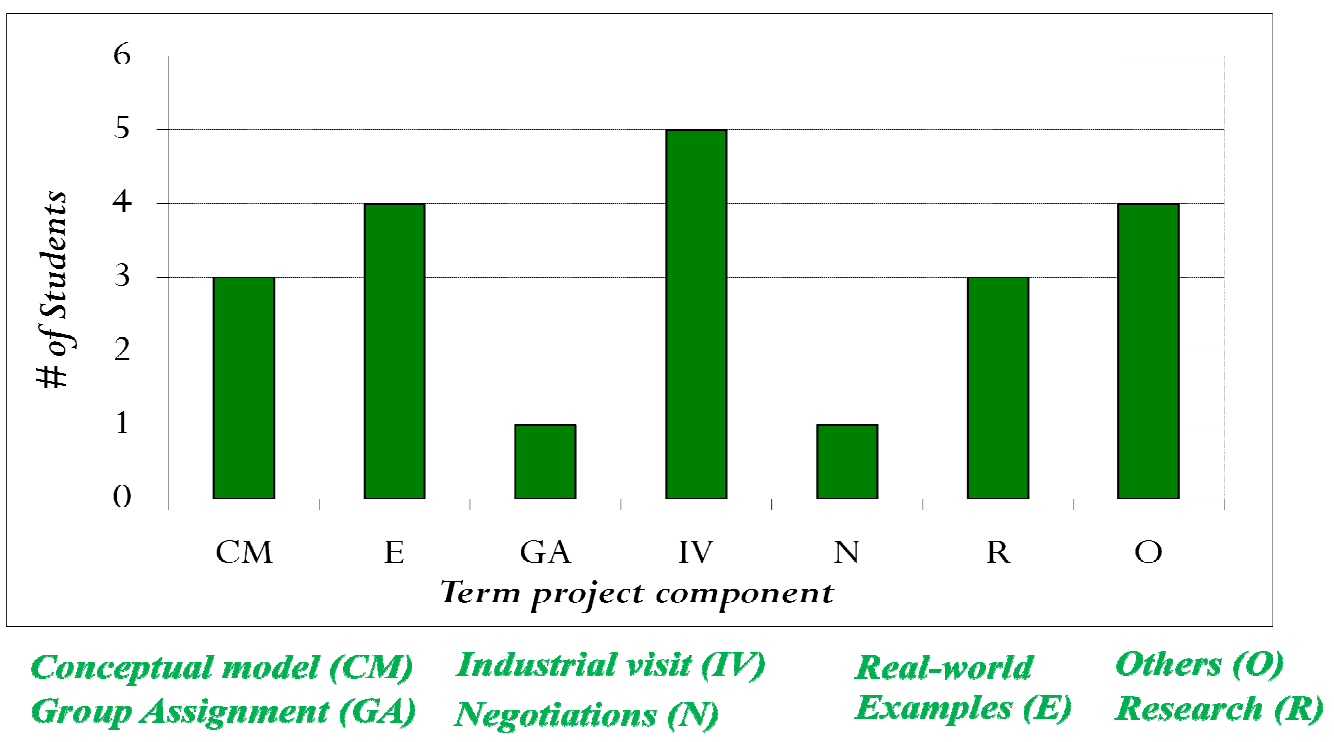

Figure 1. Term project and course components that helped students most in connecting theory with practice. 


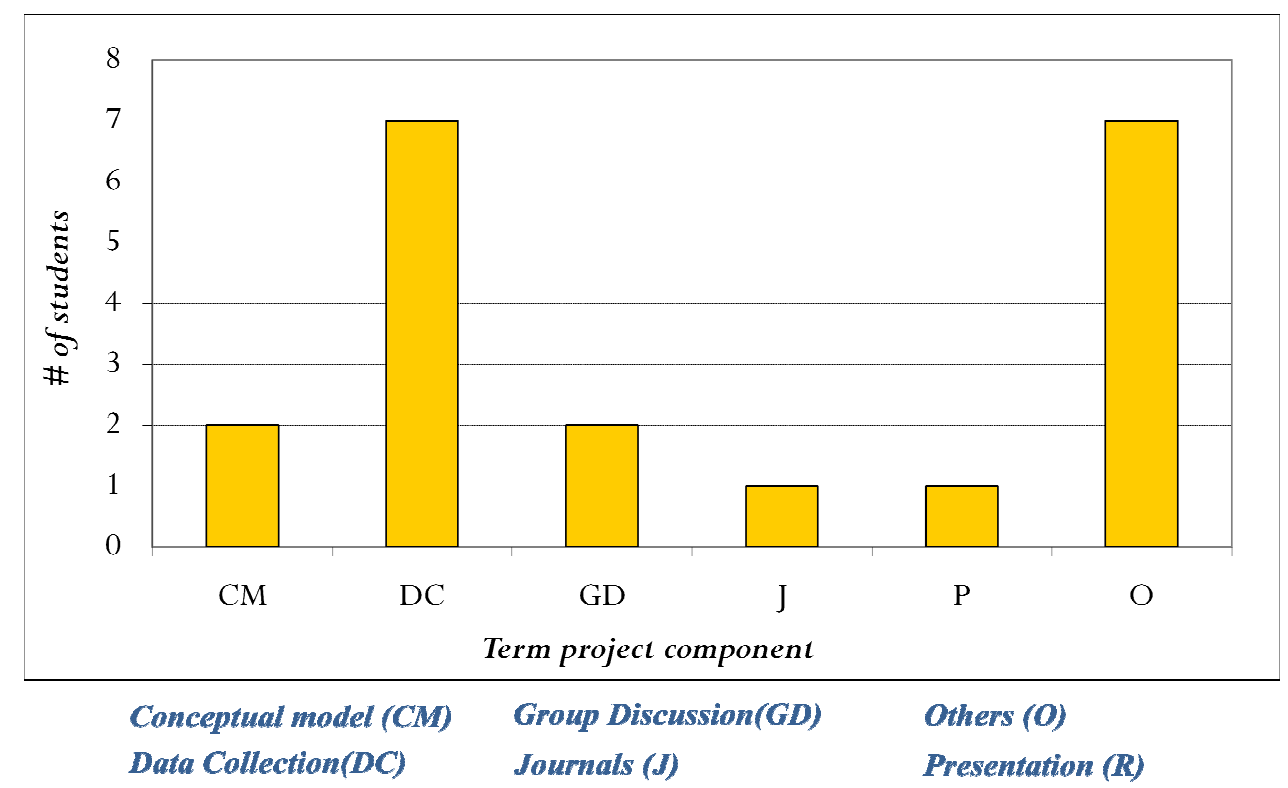

Figure 2. Components of the Course that are least helpful to students in connecting theory with practice.

\subsection{Impacts of Industrial Visit on Students' Ability to Connect Theory with Practice}

Industrial site visits help students to bridge abstract and real worlds. Many of the participating students specifically indicated in their reflective reports, end of semester survey and in their term project reports that seeing how what they were taught in the classroom being implemented in the real world helped them to learn. The following students' comments reflect how several students described their thoughts about impacts of term projects on their ability to connect theory with practice:

"Industrial visit helped me learn most. It gives me a better understanding of something when I see it in real life."

"I now have a much clearer understanding of how different industries can work together, and provide her products and services. I think with more instruction, practice and other field trips I will be able to think critically in almost any industry and use my chemical and biological back ground to identify the opportunities of waste recycling. I understand how communities, companies, industries, municipalities and governments all can play a role or have an impact on an eco-industrial development".

"Although the tour of company A only introduced one component of a very large spectrum in relation to eco-industrial development, the fact that it was hands on made it much easier to apply to my experience in the environmental science field, as opposed to an indirect source such as a website, and therefore is much more beneficial to my career preparation."

"Our industrial visit provided an opportunity to apply what we're learning about to a real scenario."

"I can now apply my in-class learning to real life scenarios. It has given me some insight into the dos and don'ts of setting up an EIP. I've gained some insight into critical analyses of EIPs and EINs."

Industrial visit was able to facilitate students' ability to connect theory with practice because as a tangible activity, it appealed to their visual and auditory senses. According to AAAS, [8] such experience makes students to grow in their ability to understand abstract concepts, reason logically, and generalize. This was also the view expressed in [7, 13]. It was highlighted in these articles that site-based experience provides students with more opportunities to successfully apply what they are learning within the context of the classroom. Consequently, these students' comments indicated that industrial visits helps students in applying the theory learned in the real world scenario.

\subsection{Impacts of Term Project on Students'Ability to Connect Theory with Practice}

Many students indicated that term projects have helped them to bridge the gab between abstracts and real worlds. The following students' comments also supported the claim that term project helps students' to connect theory with practice:

"This project has provided me with firsthand experience in implementing eco-industrial principles. It was like having on the job training with guidance from the instructor. This project has helped me determine how to approach the implementation of eco-industrial principles in terms of knowing what to research and what sort of information to gather, who to talk to and most importantly what specific/types of questions to ask them in order to obtain the necessary qualitative and quantitative information."

"I can now apply my in-class learning to real life scenarios. It has given me some insight into the dos and don'ts of setting up an EIP. I've gained some insight into critical analyses of EIPs and EINs."

"I can now look at any company, find out what they produce or need and be able to find solutions in which they can reduce waste or create an exchange with another company whether it is directly located nearby or in close proximity where resources can easily be shared with minimal 
transportation cost or shared cost with yet another company."

"This project has provided me with further understanding of the course material provided in the lectures. Not only will I remember this course material, it will help me implement it in real situations."

"Seeking networks and exchanges of materials is a key principle of EINs - this project helped make it clear of where to start when looking for such networks. You have to think very creatively and innovatively in order to find solutions that at first glance aren't visible. It is definitely challenging, and I think in the real world this would take years of preparation in order to facilitate networks."

"I now have a much clearer understanding of how different industries can work together, and provide other products and services."

All these comments are in line with the findings of Daniels and Asplund [14]. The report indicated that project based capstone courses provides motivation and incentive. It was also said that "students see the experience as valuable with respect to their future job prospects". Furthermore, it provides the excitement of creating something substantial. Moreover, it provides plenty of situations in which the "students learn from the other students, and they spur each other to work with the project". It was further said that such projects have "the potential for continued collaboration, gives an insight into the current practices and tools used in industry, as well as the problems in which industry is interested." In addition, "this type of course does not only provide students with real experience of their future profession, but also provides a means of exposure to silent knowledge about how to function in their future roles in industry".

\section{Conclusion}

Results of this study revealed that term project and many of the term project components in the principles of eco-industrial development course help students to connect theory with practice. It also enabled students to see how EIPs develop and function in the real world. In addition, industrial visit has the highest impacts on students' ability to connect theory with practice. Further studies and analysis would be required to determine the role of term project structure on students' ability to connect theory with practice.

\section{Acknowledgements}

The author would like to acknowledge the opportunity and support given by Institute of Scholarship and Learning and Faculty of Teaching and Learning at Mount Royal University, Calgary to undertake this study. He would also like to thank all students that participated in the study.

\section{References}

[1] L. Helle, P. Tynjälä and E. Olkinuora, "Project-Based Learning in Post-Secondary Education: Theory, Practice and Rubber Sling Shots." Higher Education, vol. 51(2), pp. 287-314, 2006.

[2] A. Gitterman, "Teaching students to connect theory and practice. Social Works with Groups," vol. 11(1/2), pp. 33-41, 1988.

[3] F. A. Korthagen and J. P. Kessels, "Linking theory and practice: Changing the pedagogy of teacher education." Educational Researcher, vol. 28(4), pp. 4-17, 1999.

[4] Harris, N. "Practice Through a Lens: A Metaphor for Planning Theory." Journal of Planning Education and Research 19(3) (2000): pp. 309-315

[5] Higgins, M. and J. Morgan. "The Role of Creativity in Planning: The Creative Practitioner." Planning Practice \& Research 15(1/2) (2000): pp. 117-127.

[6] Gunder M. "Relating Theory to Practice in Planning Education: A New Zealand Approach". First World Planning Schools Congress, Shanghai: Tongji University July 11th -15 th , 2001.

[7] D.H. Allsopp, D. DeMarie, P. Alvarez-McHatton and E. Donne, "Bridging the Gap Between Theory and Practice: Connecting Courses with Field Experiences. Teacher Education Quarterly, Winter 2006, pp. 19-35.

[8] American Association for the Advancement of Science (AAAS), Science for all Americans: Project 2061. New York: Oxford University Press, 1990.

[9] Tsang, A.K., "In-class Reflective Group Discussion as a Strategy for the Development of Students as Evolving Professionals," International Journal for the Scholarship of Teaching and Learning, vol. 5 (1), pp.1-20, 2011. Retrieved in May 2012 from http://www.georgiasouthern.edu/ijsotl.

[10] R. P. Cote and E. Cohen-Rosenthal, "Designing eco-industrial parks: a synthesis of some experiences." Journal of Cleaner Production 6 (1998) 181-188.

[11] E. Lowe and J. L. Warren. The Source of Value: An Executive Briefing and Sourcebook on Industrial Ecology. Richland, Washington: Pacific Northwest National Laboratory, 1996.

[12] E. Cohen-Rosenthal, T. McGalliard and M. Bell, "Designing Eco-Industrial Parks," Accessed online on 15 January 2013 at http://teclim.ufba.br/jsf/ecodesign/dsgn0205.PDF.

[13] L. Andresen, D. Boud and R. Cohen, "Experienced-based learning," In: G, Foley. (Ed). Understanding adult education and training, 2nd ed. Sydney: Allen \& Unwin, 2000, pp. 225-239.

[14] M. Daniels and L. Asplund, "Full Scale Industrial Project Work, a one semester course," In the proceedings of the 29th ASEE/IEEE Frontiers in Education Conference, November 10 - 13, 1999 San Juan, Puerto Rico. 